from a constructional point of view, totally wrong, and this is proved by the fact that even these slides are ground to fit in the first course of manufacture, and that the springs are cut and adjustment screws provided afterwards in order to take up the looseness and shake which has already developed before the instrument has left the workshop; this will be borne out by any person with practical experience.

The perfectly constructed and accurately machined slide bearings adopted on the Continental microscopes only require slight grinding in, and consequently last for a considerably greater length of time, and if returned to the maker for readjustment, the substage, condenser, and objectives are recentred by any house which has a reputation worth maintaining.

Objectives provided with correction collars are now almost a thing of the past, as cover-glasses of a near definite thickness are no longer difficult to obtain, and what slight correction may be necessary can be effected by an easy working draw-tube of the sliding type, which can be adjusted to a nicety by adopting a twisting motion when moving the tube either up or down.

London, February ig.

F. R. BRand.

\section{On Martian Detail}

THE present seems to me a fitting time to publish the results of nearly three years' investigation of the above subject. In the pursuit of this investigation I have visited most of the principal observatories in the world and tested their seeing conditions, and I conclude categorically that the climate at Flagstaff is immeasurably superior to that of any other observatory with which I am acquainted. At Flagstaff-by the means which experience has proved to be the best-Mars is so well seen that it is difficult to believe it the same planet, the grotesque caricatures of which are apt elsewhere: to mislead the observer.

No one elsewhere seems to have realised the fundamental postulates of visual work, the first of which is that small apertures always define better than big, and that if we set a minimum of 12 to $1_{5}$ in. any increase on this causes a loss of defining power.

That this is not generally known is witnessed by the scepticism of the leading optician of the firm of Alvan Clark, which, however, vanished when he performed the experiment here a few years ago. It is therefore a priori impossible to corroborate with vast apertures of 30 to 60 in. the results to which the smaller ones have led us.

In the face of the postulate above stated, it is impossible to believe the work of great apertures. It would be difficult to see why' so much confidence has been placed in them were it not for the fact that those who uphold them have up to now never tested the truth of our postulate.

I have even met observers who averred that dark glasses were unnecessary when the planet dazzled the eye.

Those who could overlook this necessity may easily be blind to all other refinements of instrument and observer. That reduction of aperture means improvement of definition may be tested by anyone at any time with any instrument, and none but the wilfully blind can fail to be convinced.

When the above precautions are duly taken the canals are seen with a geometric reality, fineness, and clearness that is amazing. When so seen, the very strangeness of the sight at once suggests and demands the explanation that they are not natural, but artificial, features of the planet-the work of reasoning beings, whose purpose we can divine. Those who discredit the immortal discoveries of Schiaparelli and Lowell have never learned how to observe them, being wilfully or accidentally without knowledge of the proper method of seeking them.

In pursuit of this investigation I have used all apertures from 2 in. to $60 \mathrm{in}$.

No doubt remains in my mind as to the objective reality of what I have seen, and therefore with entire confidence I endorse the discoveries of Schiaparelli and the further advances made by Lowell in the same investigation. The latter has also set forth what I deem the only rational No. 2208, VOL. 88] explanation conceivable to account for this most amazing concatenation of observed phenomena.

Further, I would point out to your readers that Lowell's explanation is the only complete and consistent one ever put forward, and that it can only be replaced by an equally complete one, and is not to be combated by the isolated and conflicting statements of biassed and partial judgment which up to now have been brought against it.

JAMES H. WORTHINGTON.

Lowell Observatory, Flagstaff, Arizona, January 22.

\section{A Simple Automatic Syphon.}

THE accompanying diagram illustrates a form of automatic syphon which has been found useful in cases where it is desirable to draw off water from the bottom of a tank at the same rate as it is supplied at the top. This is particularly important when the water has to be kept saturated with air.

The diagram represents an ordinary syphon of glass tube, the opening into the tank being ground to the form of a cone. Above this end is a float, consisting of a glass bulb and open glass stem filled with air. The lower end of the stem is ground to fit over the conical end of the syphon. Water thus escapes from the bottom of the tank through the annular space between the ground portions, and the float automatically adjusts itself so that the rate of flow of water through the syphon is exactly the same as the rate at which water enters the tank. Should the supply of water cease, the float sinks and closes the syphon.

The syphon is conveniently fixed by passing one limb through a cork cemented on to the outside of the tank. The weight of the tube maintains the float in a vertical position, while the ground end of the syphon tube keeps it stationary in the tank.

Charterhouse, Godalming.

J. C. THOMson.

\section{Glazed Frost.}

During the two winters that $\mathrm{I}$ lived in Massachusetts, glazed frosts, or " ice storms" as they were called there were of comparatively frequent occurrence. I can recall three or four at least.

The ice storm always came after a period of very cold weather, when the temperature had been down to zero or below for some days. Suddenly the frost would break, and the thermometer rose to $32^{\circ}$ or $33^{\circ} \mathrm{F}$., the sky became overcast, and a heavy drizzle began to fall, driving before a slight wind, usually from the west. As the rain fell it froze in a clear layer upon everything exposed to its course. Trees, pavements, tram-lines, and overhead wires were covered in an hour or two to as much as I inch in thickness. The trams and trains had to stop running owing to the state of the rails, whilst even the thick trolley wires were unable to support the weight of the incrustation, and branches as much as 6 inches thick were broken from the trees everywhere.

The storms always came on in the morning. About noon the rain stopped, the clouds cleared away, and the sun came out. The diamond-coated branches, with showers of silvery drops falling from them, against the dark blue American sky made a scene the beauty of which can scarcely be imagined.

Io Marsden Street, Manchester, February I6.
W. ERMEN. 